Research Article

\title{
The Effect of Intersection Angle on the Failure Mechanism of Utility Tunnel
}

\author{
Li Fangtao, ${ }^{1}$ Qiyao Wang, ${ }^{1,2}$ Zhiping Hu $\mathbb{D}^{1,2}{ }^{1,2}$ Zhang Yonghui, $^{1}$ Ren Xiang, ${ }^{1}$ and An Xuexu ${ }^{1}$ \\ ${ }^{1}$ School of Civil Engineering, Chang'an University, Xi'an 710061, China \\ ${ }^{2}$ Institute of Underground Structure and Engineering, Chang'an University, Xi'an 710061, China \\ Correspondence should be addressed to Zhiping Hu; huzhping@chd.edu.cn
}

Received 20 May 2020; Revised 19 July 2020; Accepted 29 October 2020; Published 26 November 2020

Academic Editor: Jia-wen Zhou

Copyright (c) 2020 Li Fangtao et al. This is an open access article distributed under the Creative Commons Attribution License, which permits unrestricted use, distribution, and reproduction in any medium, provided the original work is properly cited.

Planning utility tunnel network in the area with geological disasters poses serious concerns, especial for the utility tunnel built in the ground fissures developed cities. Many prevention and control measures have been taken when the utility tunnel crossed the ground fissures, such as finding the right intersection angle when planning the utility tunnel. In order to study the effect of intersection angle for utility tunnel when crossing ground fissures, this paper compares outcomes when the utility tunnel crosses ground fissures with different intersection angle through numerical simulation method. Because actually the intersection angle of utility tunnel and ground fissures is varied, in order to make stress-strain relationship of the model more realistic, a trilinear mode of reinforcing bar stress-strain relationship was established, and the material property of utility tunnel and soil were assigned to concrete damaged plasticity and Mohr-Coulomb plasticity, respectively. The simulation result shows that the axial tension stress and vertical shear stress of utility tunnel are increased with the increasing of intersection angle, but displacement and shear stress of utility tunnel in horizontal direction are increased with the decreasing of intersection angle. The variation of intersection angle of utility tunnel and ground fissures cannot significantly reduce the damage of utility tunnel. The vertical displacement of utility tunnel does not vary with intersection angle. Finally, this paper suggests that the strengthening length of utility tunnel should not be less than 50 meters (10 times the height of utility tunnel) on both sides of the ground fissures no matter the variation of intersection angle.

\section{Introduction}

A utility tunnel is a lifeline passage of the city built underground or above ground to carry utility lines such as electricity, steam, water supply pipes, and sewer pipes (Figure 1). The construction of utility tunnel has a history of more than a century in developed countries. China is a big developing country, and, due to the shortage of land and increasing population, there is an urgent need to develop utility tunnel construction to replace traditional pipeline construction in order to save resources [1]. Since 2013, the State Council of China has intensified the construction of utility tunnel and established pilot cities of utility tunnel construction. Xi'an, as one of the pilot cities, has been carrying out a large number of utility tunnel projects. However, it is well known that Xi'an is a city with very developed ground fissures disasters [2, 3]. Ground fissures can cause a significant damage to farmland, roads, buildings, and other infrastructures $[4,5]$. So it takes a great risk to carry out any engineering under the ground fissures activity, especially for the metro and utility tunnel. Figure 2 shows the distribution of ground fissures, metro planning network, and utility tunnel planning network in Xi'an. For a long time, ground fissure has been a central issue in the construction of metro and utility tunnel in Xi'an.

Ample researches have been conducted on utility tunnel and measures for prevention of ground fissures. From literature review, the researches on utility tunnel were almost focused on planning, dynamic response, management, failure mechanism, and so forth [6-8]. The problem of utility tunnel construction does not lie in technology but lies mainly in planning, government policies, and special 


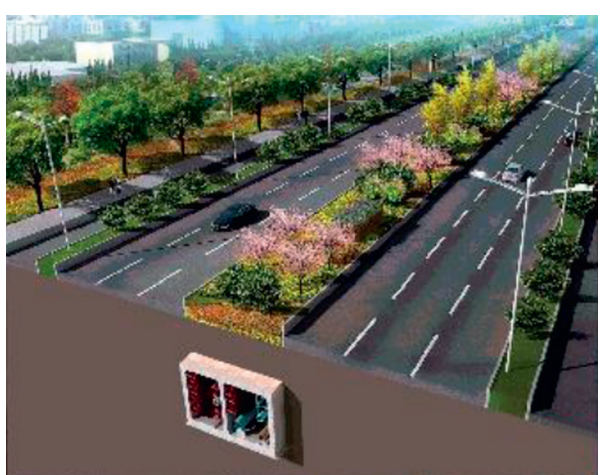

(a)

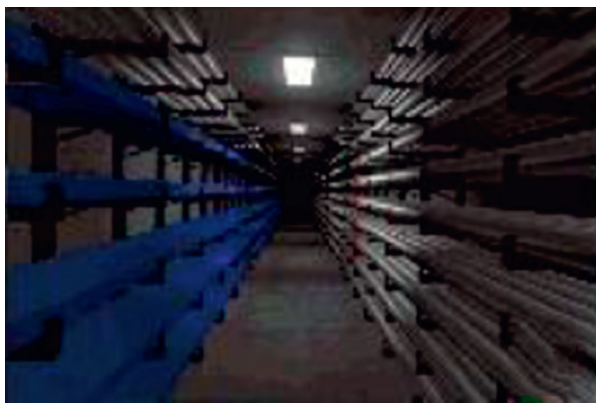

(c)

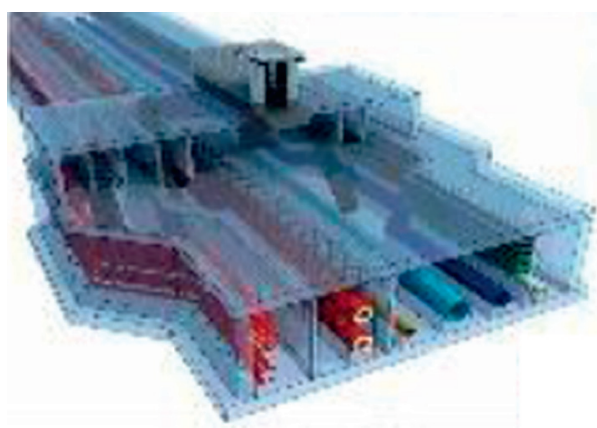

(e)

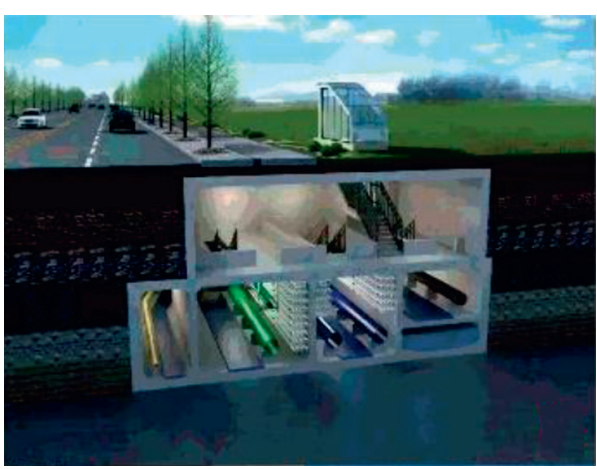

(b)

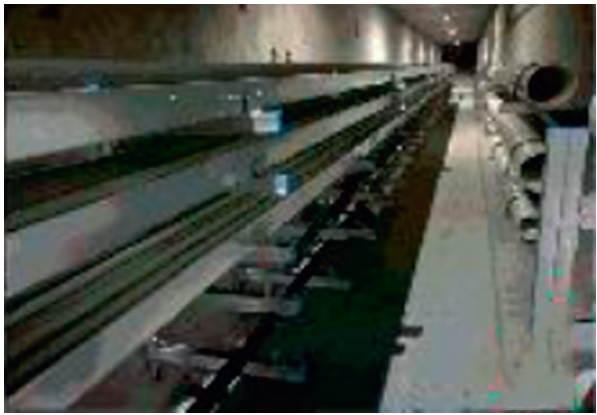

(d)

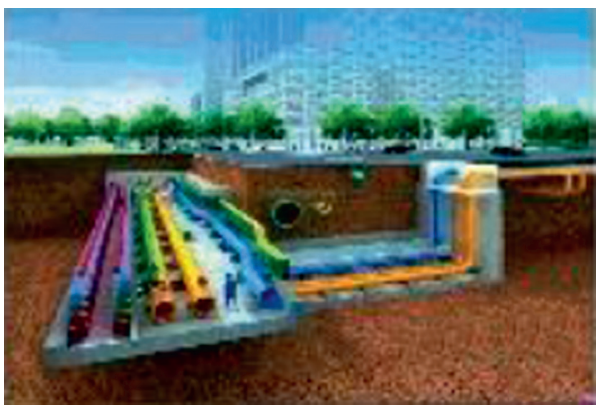

(f)

FIGURe 1: Utility tunnel. (a) Single-floor utility tunnel. (b) Double-floor utility tunnel. ((c) and (d)) Utility lines inside the utility tunnel. ((e) and (f)) The section of utility tunnel.

geological hazards. In order to optimize utility tunnel plan, a series of design rules and methods have been proposed by Julian. He analyzed how compatibility of utility system networks with highway system networks could be greatly improved by appropriate attention to utilidor systems in urban planning [9]. Moreover he advised an expert system combining color-coded scales and Delphi and AHP (analytic hierarchy process) methods to analyze criticality and threats on utility tunnels to support planning of security policies for utilities in urban subsurface [10]. A'WOT (Weaknesses, Opportunities, and Threats) hybrid method combining SWOT (Strengths, Weaknesses, Opportunities, and Threats) analysis and analytical hierarchy process (AHP) also was applied to study utility tunnel planning in urban areas [11]. Chao et al. have given some practical experience for decision-making, planning, construction, management, and other aspects based on the analysis of several construction cases [12]. Chen predicted the dynamic characteristics of the soil and response of utility tunnel through three-dimensional numerical simulation for large-scale shaking table test [13]. In addition, the dynamic response of utility tunnel during the passage of Rayleigh waves was studied by scholars [14]. Although the technology of utility tunnel construction is mature, it still needs lots of researches when utility tunnel is under special geological hazard conditions of ground fissures. The common tunnel failure mechanism when crossing ground fissures was studied by scholars; moreover, some proposals to the ground fissures encountered in urban metro construction in Xi'an have been given through the experiments conducted by scholars [15-17]. Figure 3 shows the common tunnel failure mechanism when crossing ground fissures; it is well known that the upper and lower surfaces of the tunnel were under tension and compression, respectively, and the tunnel shows bending-torsional and 


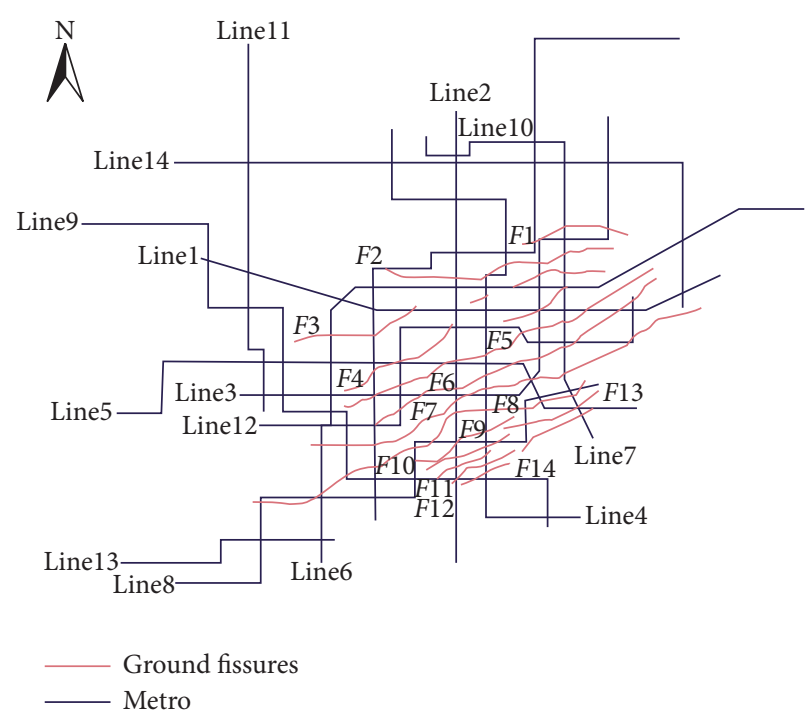

(a)

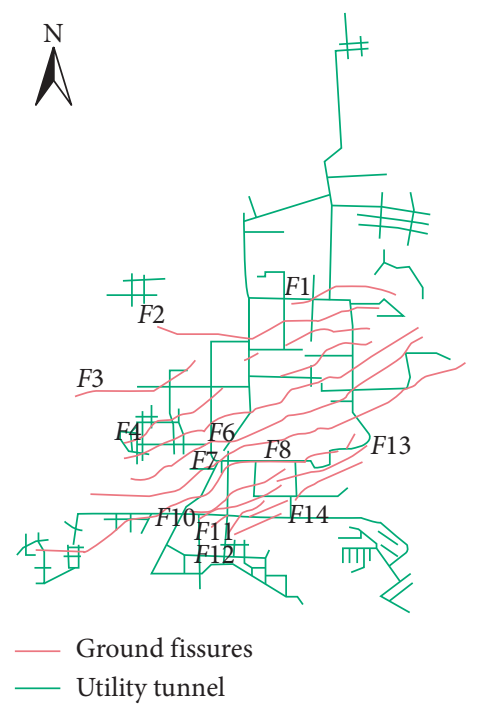

(b)

Figure 2: (a) Distribution of ground fissures and the metro planning network in Xi'an city. (b) Distribution of ground fissures and the utility tunnel network in Xi'an city.

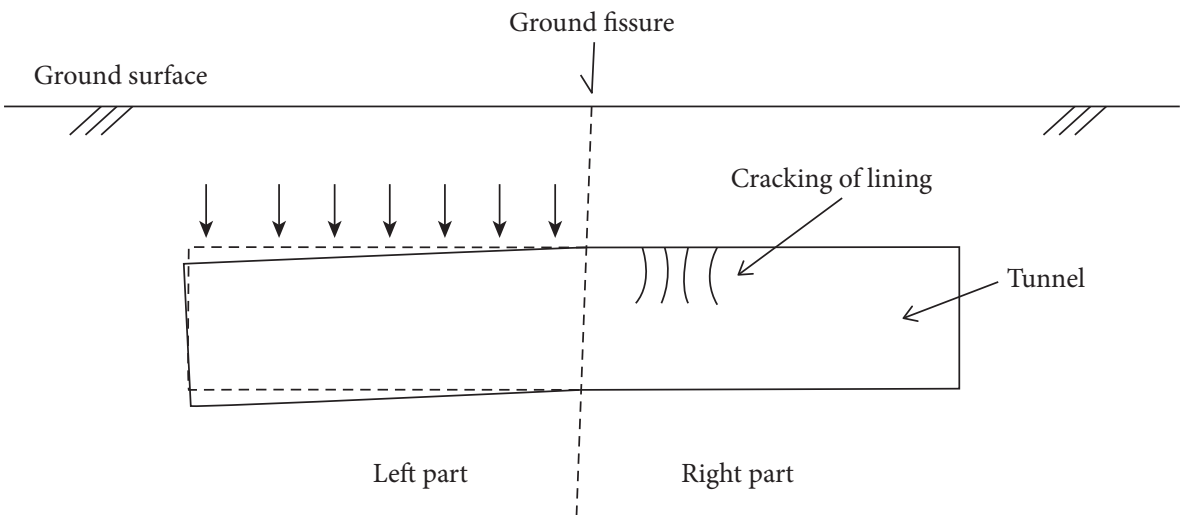

(a)

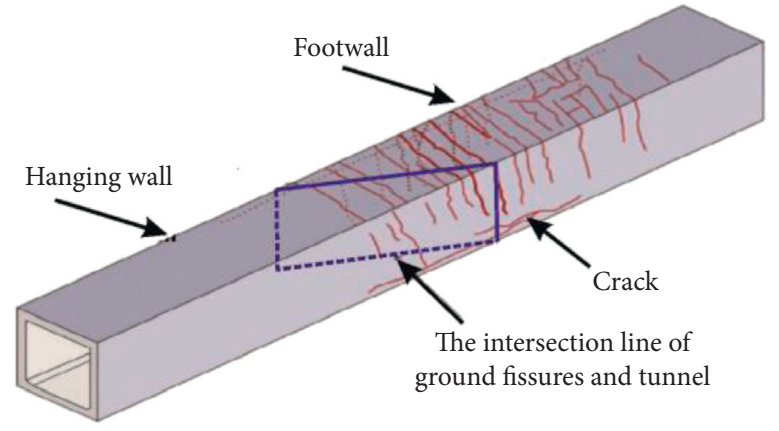

(b)

Figure 3: Continued. 


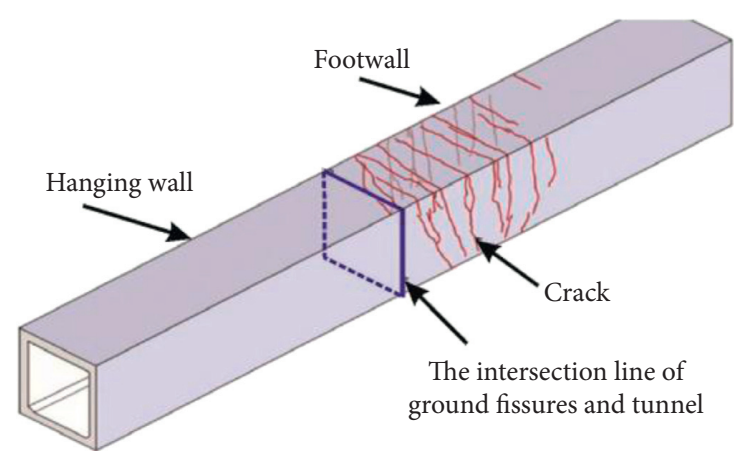

(c)

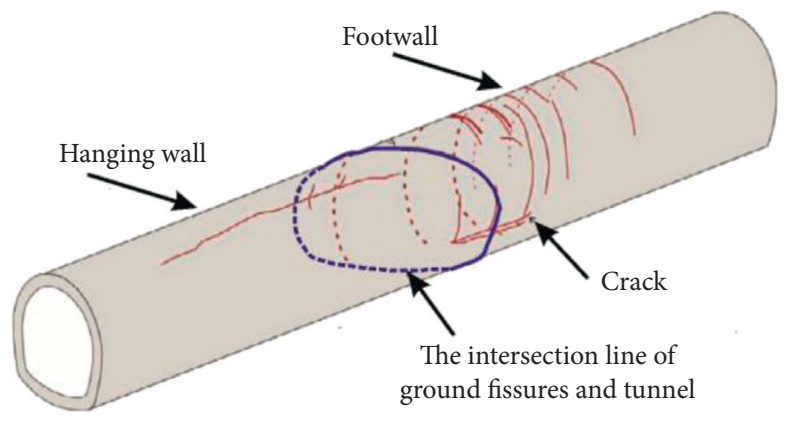

(d)

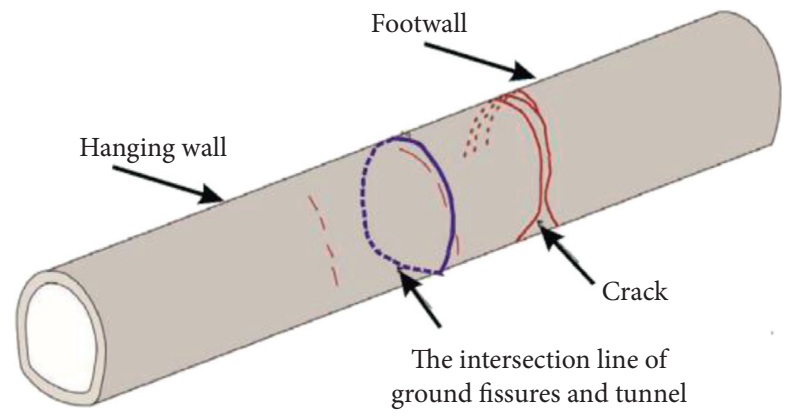

(e)

Figure 3: Common tunnel failure mechanism when crossing ground fissures. (a) The section of tunnel crossing ground fissures. (b, c) Previous study of open-cut box tunnel failure mechanism when crossing ground fissures. (d, e) Previous study of horseshoe-shaped tunnel failure mechanism when crossing ground fissures.

shearing failure under oblique intersection conditions. Many scholars suggested that the utility tunnel and ground fissures should be intersected at about a 90-degree angle in planning. However, it is not realistic in construction because the intersection angle of utility tunnel and ground fissures is varied. In addition, due to the limitation of experiment funds and size of test model, few researches have been conducted on the effect of intersection angle on the failure mechanism of utility tunnel.

In order to study the effect of intersection angle on the failure mechanism of utility tunnel, this paper compared the stress redistribution, deformation characteristics, equivalent plastic strain, and failure mechanism of utility tunnel with different intersection angle through numerical analysis. Many scholars have solved engineering problems by using numerical analysis method due to its advantages of high efficiency, high accuracy, and low cost [18-21]. Because this method is not limited by the experimental funds and size of test model when carrying out so many researches, the study can optimize the design of utility tunnels built in ground fissures area.

\section{Numerical Methodology}

This study simulated the failure mechanism of utility tunnel crossing ground fissures with different intersection angle through finite element software of ABAQUS. ABAQUS is widely regarded as the most powerful finite element software, which can analyze complex solid mechanical structural mechanical systems. The version of finite element software in this paper is ABAQUS 6.14. According to the actual conditions, different intersection angle was simulated with the same activity of ground fissures. In order to make stressstrain relationship of the model more realistic, a trilinear mode of reinforcing bar stress-strain relationship was established, and the material properties of utility tunnel and 
soil were assigned to concrete damaged plasticity and MohrCoulomb plasticity, respectively.

The simulation was grouped into five categories based on the intersection angle of utility tunnel and ground fissures: model $A$ was $30^{\circ}$, model $B$ was $45^{\circ}$, model $C$ was $60^{\circ}$, model $D$ was $75^{\circ}$, and model $E$ was $90^{\circ}$. These models almost covered all the actual situations of utility tunnel crossing ground fissures. In order to compare the failure mechanism of utility tunnel with the same activity of ground fissures, the main parameters such as material property of the model, geometry size of the model, boundary conditions, and ground fissures activity remained unchanged in each of the models. Because of nonlinear structure in reinforced concrete and the shape of the soil part in model $A$ being more irregular than other models, model $A$ was simulated first. If computation in model $A$ gains a good convergence, the convergence will be easy in other models. At last, stress, deformation, equivalent plastic strain, and failure mechanism of utility tunnel were analyzed and compared. Although the numerical simulation has some defects compared to experiments, the failure mechanism of utility tunnel is credible when the simulation results well agree with the prior experiments' results.

2.1. Numerical Model Description of the Utility Tunnel. Double-storage rectangular utility tunnel was selected to simulate due to it being a typical underground structure and being wildly used in utility tunnel design. The size of the utility tunnel and soil mass are shown in Figure 4 . The stressstrain property of reinforced concrete of simulation mode is nonlinear based on the Standards of Concrete Structure Design (GBJ10-89) for China, so that failure mechanism will well agree with actual situations [22]. Concrete damage plastic property is assigned to concrete and a trilinear mode of reinforcing bar stress-strain relationship was established singly.

In this model, the uniaxial compressive strength is $f_{\mathcal{c}}, r$ of concrete is $50 \mathrm{MPa}$, and corresponding strain is $1.92 \times 10^{-5}$. Table 1 shows the detailed parameters of concrete damage plastic model. Figure 5 shows the stress-strain relationship of reinforced concrete of utility tunnel. The damage parameters and stress of concrete compression were calculated as follows:

$$
\begin{aligned}
\sigma & =\left(1-d_{c}\right) E_{c} \varepsilon, \\
d_{c} & = \begin{cases}1-\frac{\rho_{c n}}{n-1+x^{n}}, & x \leq 1, \\
1-\frac{\rho_{c}}{\alpha c(x-1)^{2}+x}, & x>1,\end{cases} \\
\rho_{c} & =\frac{f_{c, r}}{E_{c} \varepsilon_{c, r}} \\
n & =\frac{E_{c} \varepsilon_{c, r}}{E_{c} \varepsilon_{c, r}-f_{c, r}}, \\
x & =\frac{\varepsilon}{\varepsilon_{c, r}},
\end{aligned}
$$

where $\sigma, \varepsilon$, and $E_{c}$ are stress, strain, and elastic modulus of concrete with plastic damage, respectively; $\alpha_{c}$ is the parameter of stress-strain curves for concrete compression; $f_{c, r}$ is the uniaxial compressive strength, $\mathrm{MPa} ; \varepsilon_{c, r}$ is the strain corresponding the uniaxial compressive strength $f_{c, r} ; d_{c}$ is the coefficient of concrete compression damage; $\varepsilon_{c, u}$ is the strain corresponding to $0.5 f_{c, r}$ in the descending part of the stressstrain curves of concrete compression.

\subsection{Numerical Model Description of the Ground Fissures.} The activity of ground fissures, dip angle, section size, and intersection angle of utility tunnel and ground fissures are important parameters for the activity of ground fissures. Referring to the investigation of ground fissures activity in Xi'an and the design code of metro (in 100-year service life), the maximum vertical displacement of ground fissures in simulation was $500 \mathrm{~mm}$. The vertical displacement restraint was applied at the bottom of hanging wall, while the bottom of the foot wall remains stationary to achieve relative movement. The dip angle of the ground fissures in simulation was $80^{\circ}$ according to the most occurrence of Xi'an ground fissures [23]. Because the geological surveys show that the dip angle of most ground fissures in $\mathrm{Xi}^{\prime}$ an is 80 degrees, the section of hanging wall and foot wall was $30 \mathrm{~m} \times 40 \mathrm{~m}$ so that the boundary effect will be very small. The model of soil was divided into three layers based on the geology investigation in Xi'an. Table 2 shows the soil parameters of each layer.

2.3. Assembly Result of Model. The instances of hanging wall, foot wall, reinforcing bar, and utility tunnel were precisely assembled. Assemble result is shown in Figure 4. Then the interaction properties of hanging wall and foot wall, hanging wall and utility tunnel, and foot wall and utility tunnel were created singly. The intersection between soil and utility tunnel was simulated through the creation of contact property between soil and utility. The contact properties include tangential behavior and normal behavior. The fraction coefficient of soil contacting concrete is 0.7 , while that of soil contacting soil is 0.3 .

\section{Simulation Result and Analysis}

3.1. Surveying Lines. For the convenience of utility tunnel failure mechanism analysis, different surveying lines were arranged on the surface and inside of the utility tunnel according to the content of the analysis. The surveying lines were along with longitudinal axis of the utility tunnel and the direction of longitudinal axis is from hanging wall to foot wall. Surveying line 1 to surveying line 4 were created based on the final deformed shape of the utility tunnel (Figure 6). The deformation of the utility tunnel is apparently presented at the edges, so these four surveying lines were assigned and labelled at edges, respectively. Surveying line 5 to surveying line 8 were assigned in the middle of the side walls and central wall with the same height. The last two surveying lines were assigned to the top of the central wall. All the surveying lines were created based on the need of analysis. 


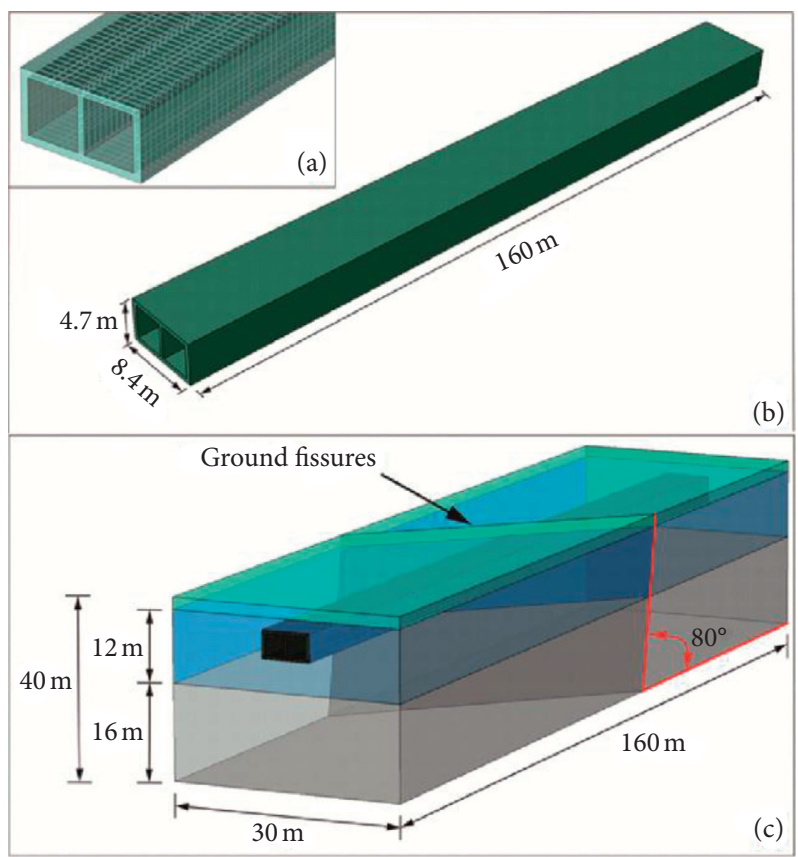

Figure 4: The model of utility tunnel. (a) The utility tunnel with reinforcing bar. (b) The size of utility tunnel. (c) Assembly result of the model.

TABle 1: Parameters of concrete damage plastic model [22].

\begin{tabular}{lccccccc}
\hline Parameters & \multicolumn{7}{c}{ Value } \\
\hline$f_{c, r}(\mathrm{MPa})$ & 40 & 45 & 50 & 55 & 60 & 65 & 70 \\
$\varepsilon_{c, r}\left(10^{-5}\right)$ & 179 & 185 & 192 & 198 & 203 & 208 & 213 \\
$\alpha_{c}$ & 1.94 & 2.21 & 2.48 & 2.74 & 3 & 3.25 & 3.5 \\
$\varepsilon_{c u} / \varepsilon_{c, r}$ & 2 & 1.9 & 1.9 & 1.8 & 1.8 & 1.7 & 1.7 \\
\hline
\end{tabular}

\subsection{Deformation Analysis}

3.2.1. Vertical Displacement Analysis. The displacement of utility tunnel is dominated by the vertical displacement of ground fissures. Although there is a horizontal displacement in the activity of ground fissures, the vertical displacement is much bigger than horizontal displacement according to the final deformation of the utility tunnel. Therefore, the vertical displacement was analyzed first. Surveying line 1 to surveying line 4 are on the edges of the utility tunnel, so these four surveying lines were selected to analyze deformation.

Due to the fact that the vertical displacement was applied on the bottom of the hanging wall, the vertical displacement of utility tunnel on hanging wall side was bigger than that on foot wall side. Figure 7 shows the vertical displacement of each surveying line relative to its end point. The deformation of the utility tunnel looked like an S-curve. Apparently, no matter how the intersection angle varied, the vertical displacement had almost no change. The vertical displacement was only related to the vertical activity of ground fissures. Compared to the horizontal displacement, the vertical displacement was much bigger than horizontal displacement. It can be concluded that the vertical displacement is the main reason for the failure of utility tunnel with different intersection angle. The shear stress in vertical direction will be greater than the shear stress in horizontal direction.

Figure 7 indicates that, accompanied with the increasing of vertical displacement, the tension stress was increased. Vertical displacement had no relationship with intersection angle and it dominated the deformation of utility tunnel. According to the analysis of the result, it is indicated that when planning the network of utility tunnel, it is useless to consider the variation of intersection angle to minimize vertical displacement.

3.2.2. Horizontal Displacement Analysis. The results obtained in the previous studies using test methodology indicated that the torsion and bending deformation occurred when utility tunnel crossed ground fissures with small intersection angle $[15,24]$. The deformation of the utility tunnel in this paper agreed well with the previous studies. Although the deformation of the structure was well known by researchers, the trend of deformation was not compared with different intersection angle. So the horizontal displacement was analyzed below.

Figure 8 shows the horizontal displacement of surveying line 1 to surveying line 4 when utility tunnel crossed ground fissures with different intersection angle. It is easy to find that the horizontal displacement was increased with the decreasing of intersection angle (Figure 9). The value of horizontal displacement was almost 0 when the utility tunnel and ground fissures intersected at a right angle. The biggest horizontal displacement was nearly $0.08 \mathrm{~m}$ when the intersection angle was $30^{\circ}$. It can be concluded that the larger horizontal displacement, the greater horizontal shear stress. It means that the horizontal shear stress was increased with the 


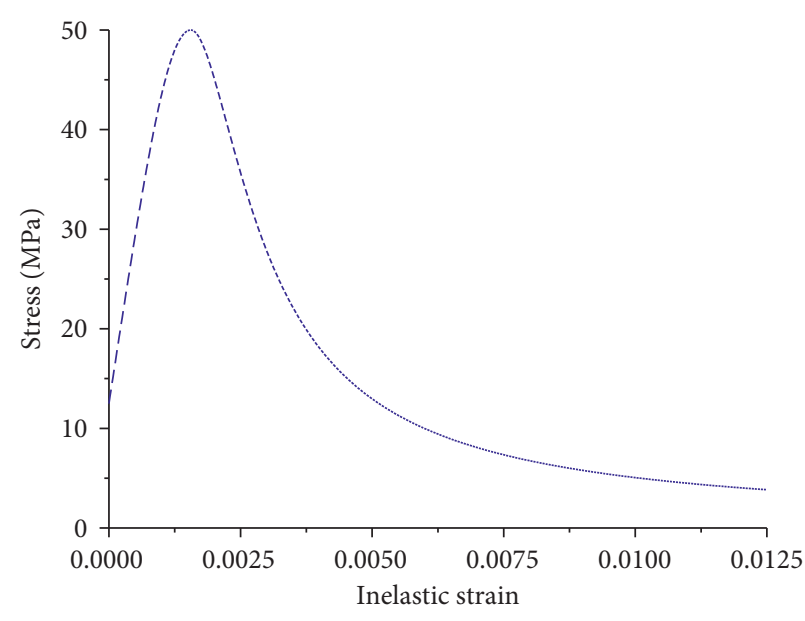

(a)

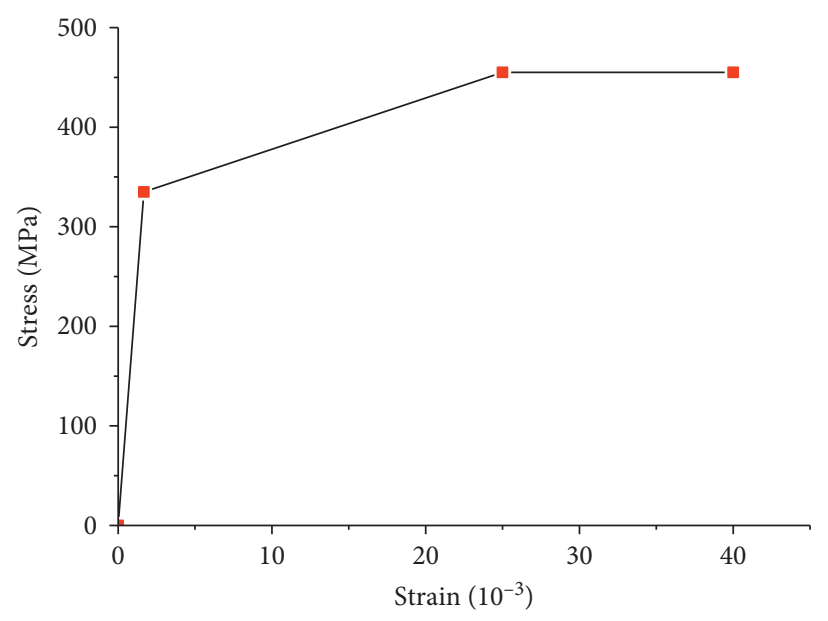

(b)

FIGURE 5: (a) Stress-inelastic strain curves of concrete. (b) Stress-strain curves of reinforcing bar.

TABLE 2: Soil parameters of each layer.

\begin{tabular}{|c|c|c|c|c|c|}
\hline Soil & Mass density $\rho\left(\mathrm{kg} / \mathrm{m}^{3}\right)$ & Elasticity modulus $E(\mathrm{MPa})$ & $\begin{array}{c}\text { Poisson's ration } \\
v\end{array}$ & $\begin{array}{c}\text { Internal friction angle } \\
\varphi\left(\left(^{\circ}\right)\right.\end{array}$ & Cohesion yield stress $c(\mathrm{~Pa})$ \\
\hline $\begin{array}{l}\text { First } \\
\text { layer }\end{array}$ & 1730 & 1.2 & 0.35 & 11 & 16000 \\
\hline $\begin{array}{l}\text { Second } \\
\text { layer }\end{array}$ & 1860 & 3.5 & 0.35 & 19 & 24000 \\
\hline $\begin{array}{l}\text { Third } \\
\text { layer }\end{array}$ & 1920 & 4 & 0.3 & 21 & 30000 \\
\hline
\end{tabular}

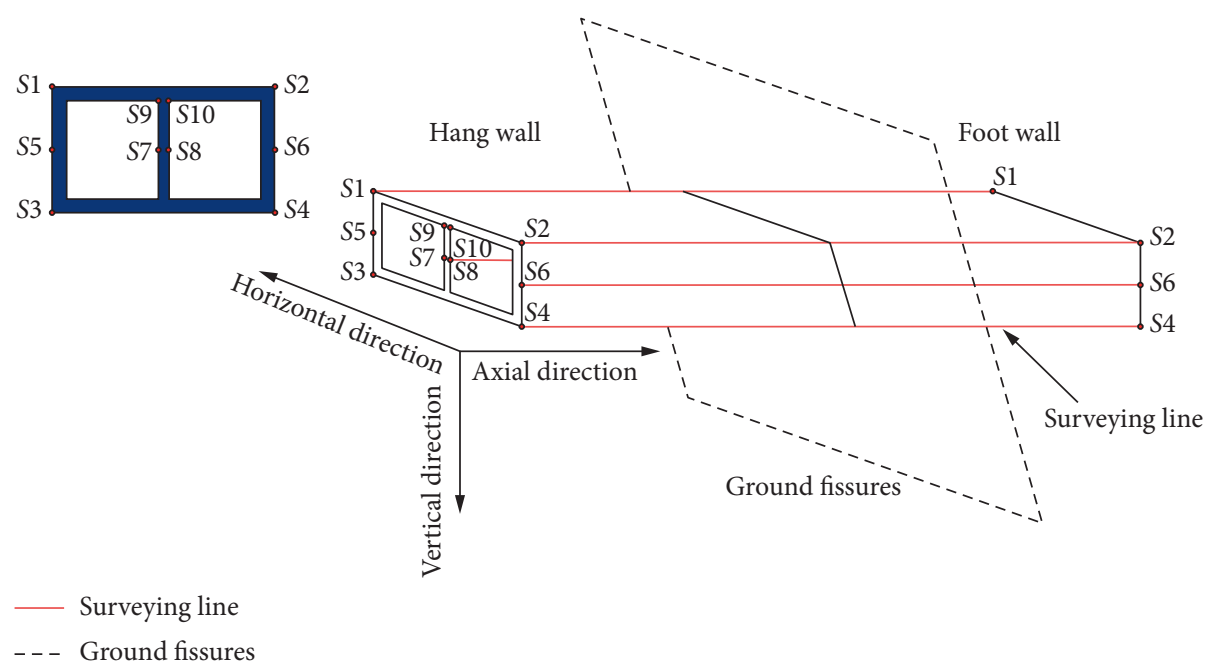

FIGURE 6: Surveying lines layout. $S 1=$ surveying line 1; $S 2=$ surveying line 2; $S 3=$ surveying line 3; $S 4=$ surveying line 4; $S 5=$ surveying line 5; $S 6$ = surveying line 6; $S 7=$ surveying line $7 ; S 8=$ surveying line $8 ; S 9=$ surveying line 9.

decreasing of intersection angle. The experiment conducted by professor Peng found that the shear stress occurred when metro crossed ground fissures with a skew angle, and the result agreed well with the previous study [15].

According to the comparison of horizontal displacement, it is indicated that the shear stress was increased with the decreasing of intersection angle. Sometimes horizontal displacement is more dangerous than vertical displacement for the utility lines carried by utility tunnel. When planning the network of utility tunnel in ground fissures area, the utility tunnel should cross ground fissures with a big intersection angle to prevent horizontal displacement, and if it is inevitable to cross ground 


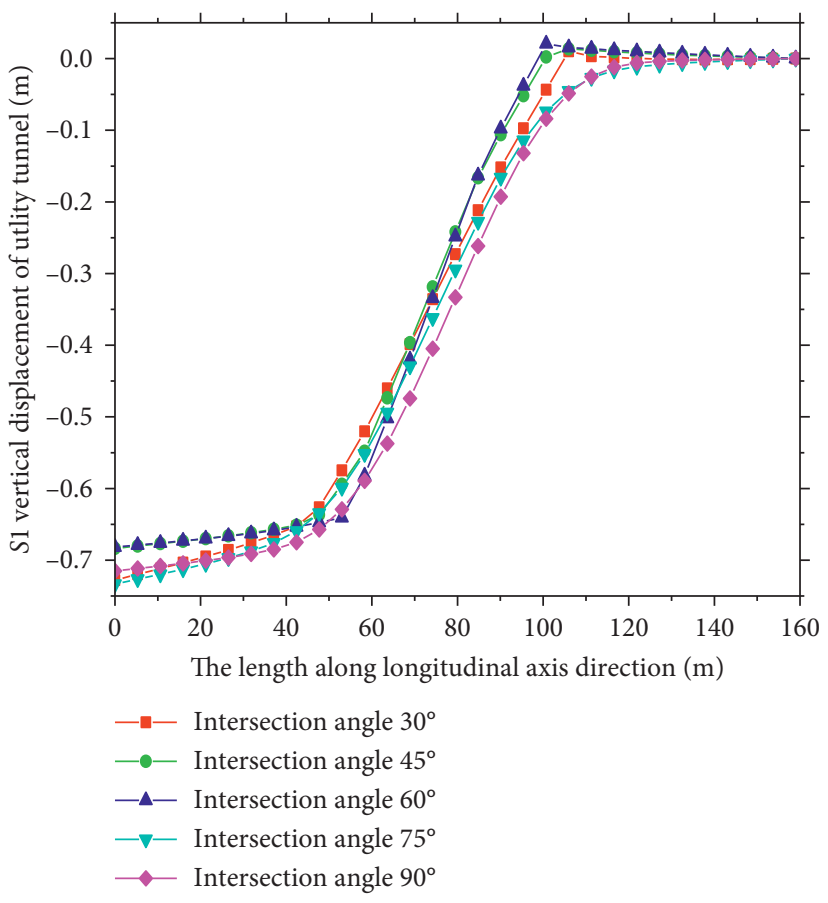

(a)

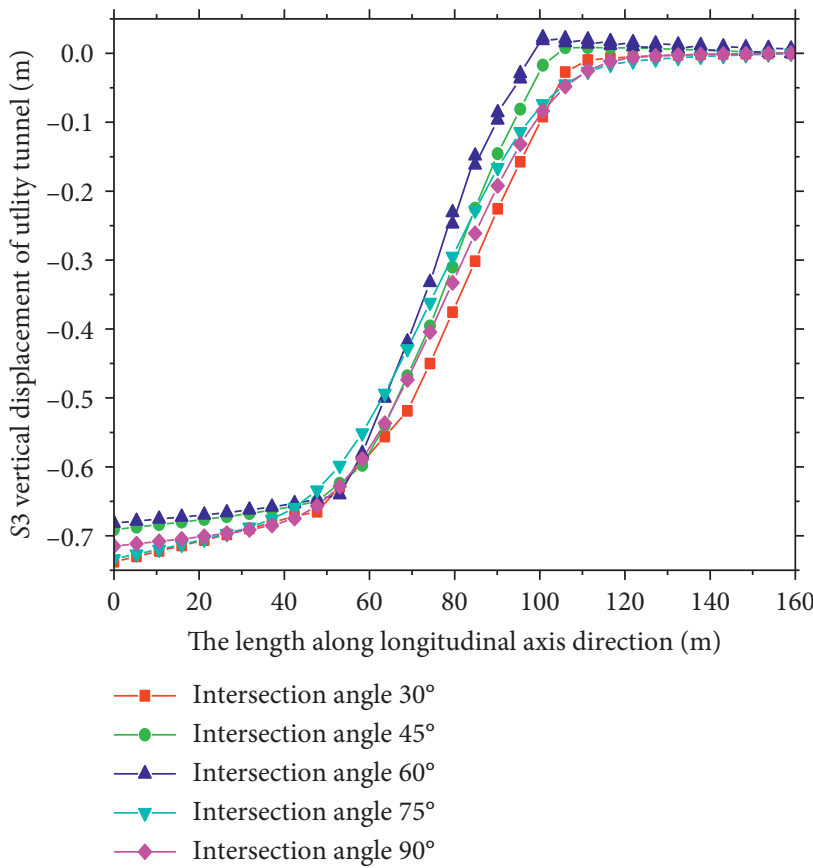

(c)

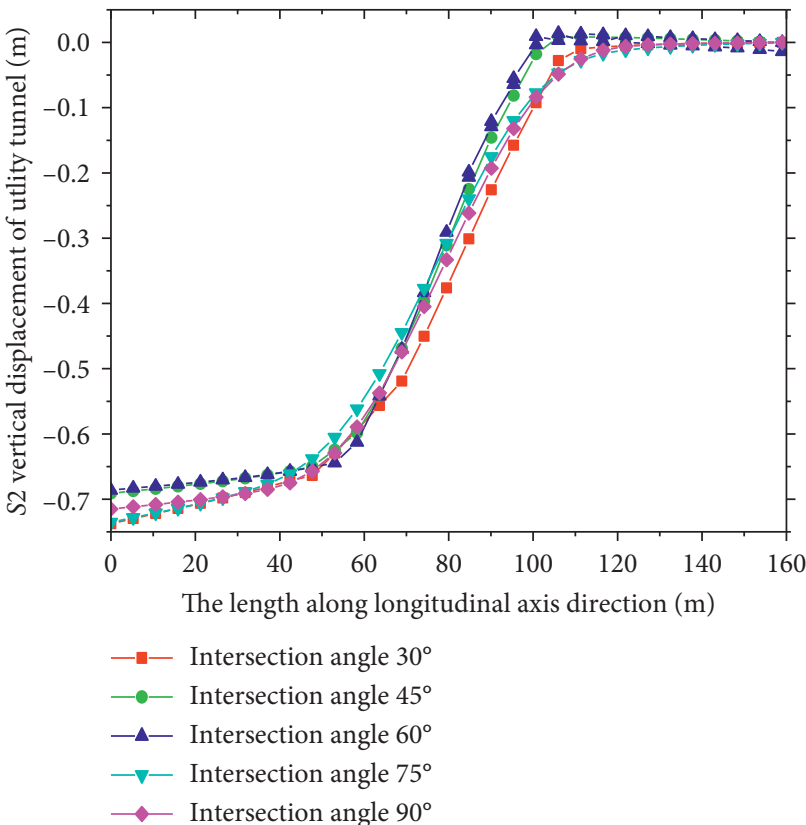

(b)

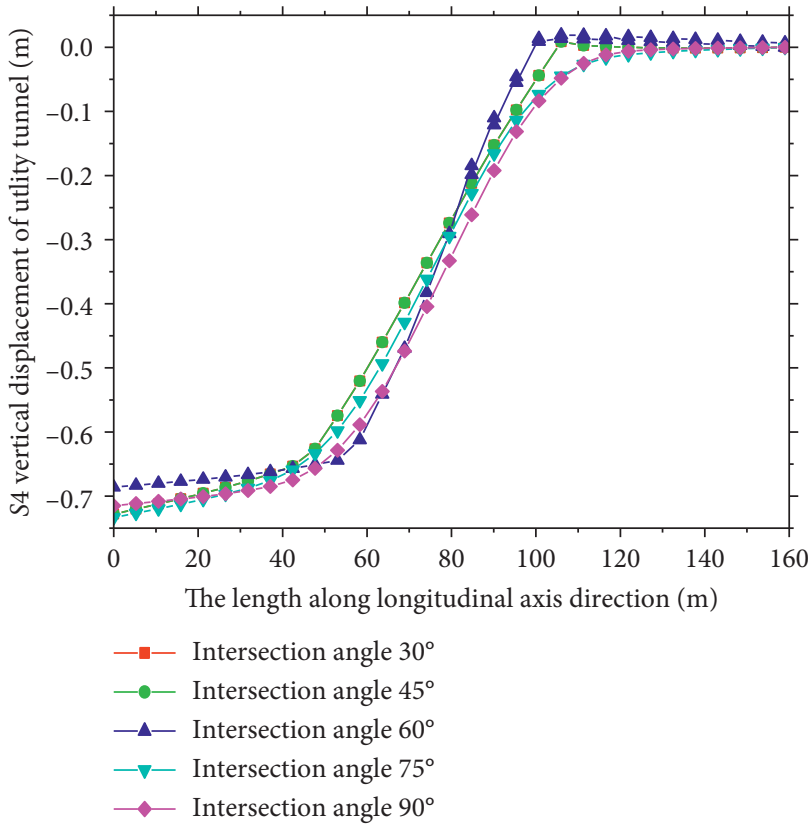

(d)

Figure 7: Horizontal displacement of each surveying line. (a) The horizontal displacement of surveying line 1. (b) The horizontal displacement of surveying line 2. (c) The horizontal displacement of surveying line 3. (d) The horizontal displacement of surveying line 4.

fissures with a small intersection angle, measures should be taken to decrease or minimize it.

\subsection{Stress Analysis}

3.3.1. Axial Tension Stress. From aforementioned analysis of deformation, it s apparent that vertical displacement was much more significant than horizontal displacement.
No matter the variation of the intersection angle, the vertical displacement almost remained unchanged. In order to find the relationship between vertical displacement and axial tension stress, surveying line 1 to surveying line 4 were selected for the analysis of the axial tension stress.

The axial stress is shown in Figure 10. It is obvious that, on the foot wall side, the tensile stress occurred on the top of utility 


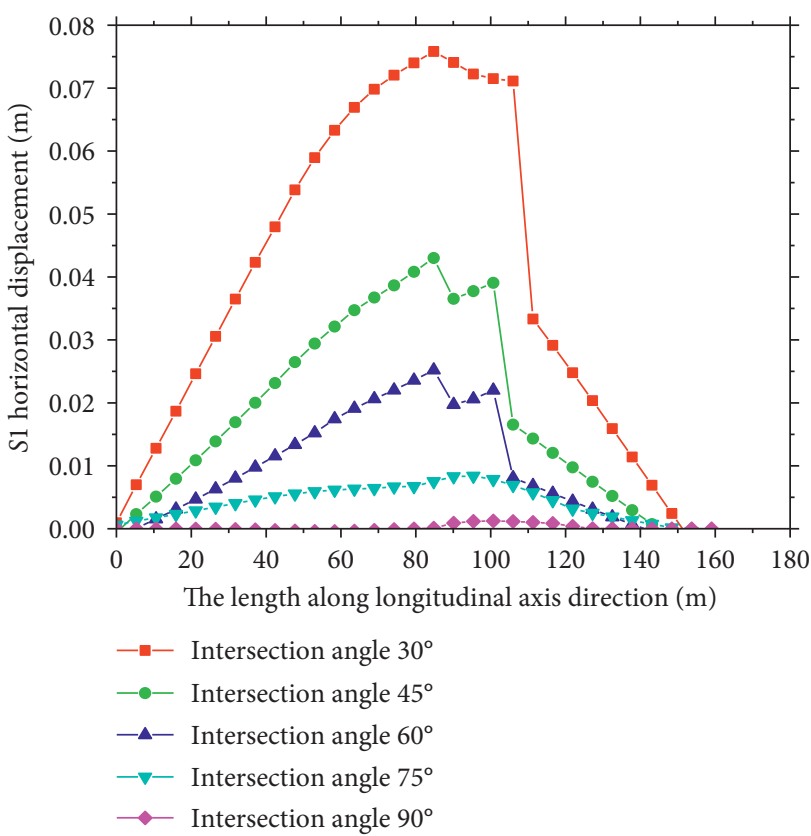

(a)

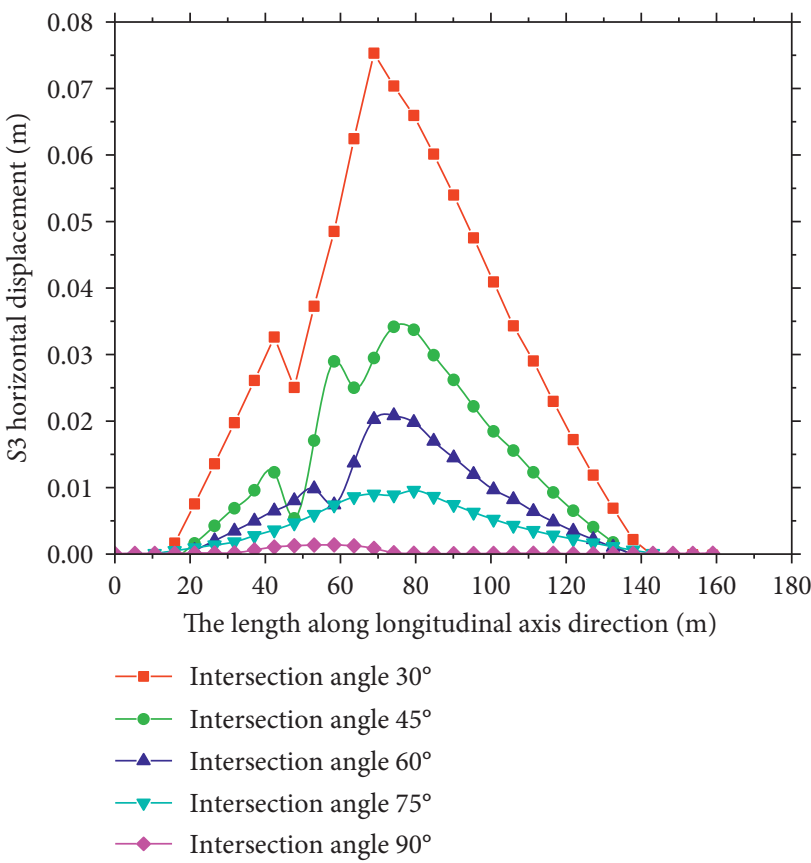

(c)

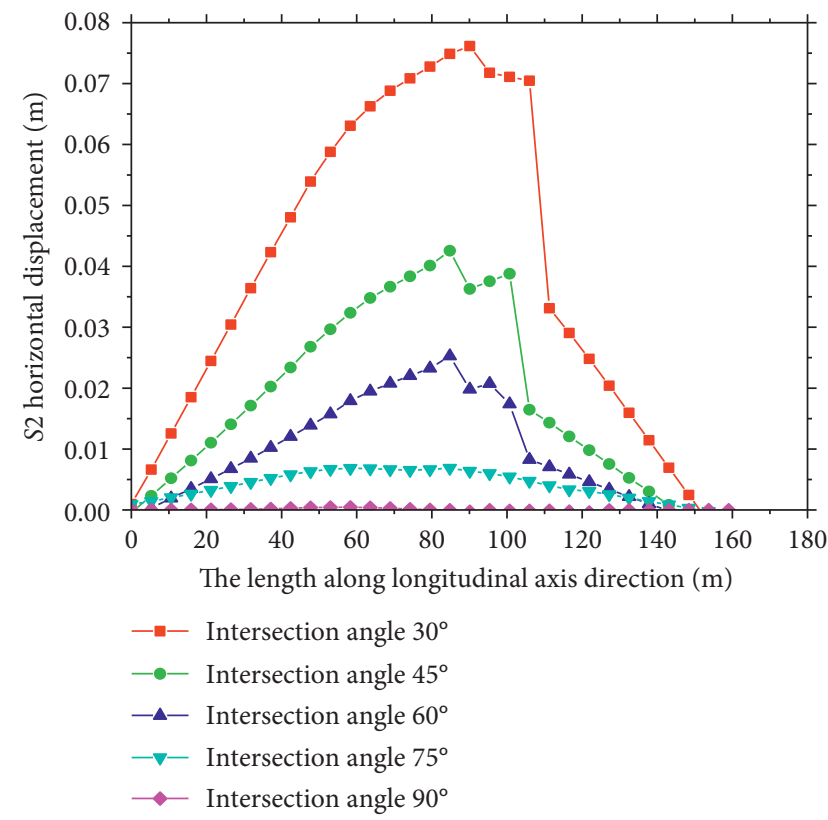

(b)

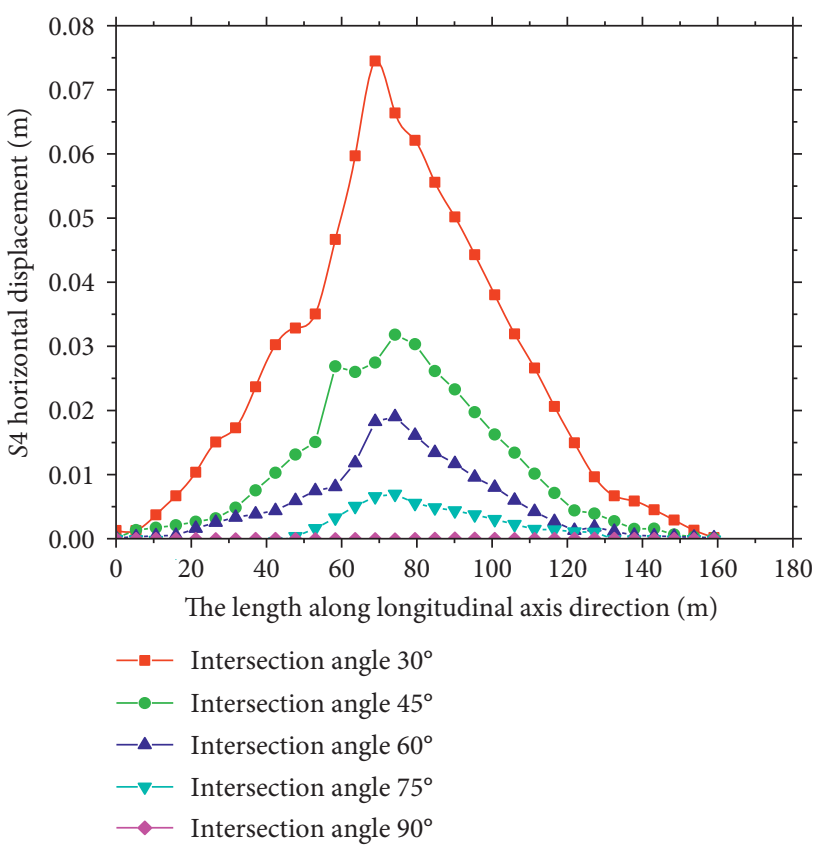

(d)

Figure 8: Vertical displacement with different intersection angle. (a) The vertical displacement of surveying line 1 . (b) The vertical displacement of surveying line 2. (c) The vertical displacement of surveying line 3. (d) The vertical displacement of surveying line 4.

tunnel, while the compressive stress occurred on the bottom. On the hanging wall side, the stress features was the opposite; the tensile stress occurred on the bottom of utility tunnel, while compressive stress occurred on the top. The stress features indicate that failure position occurred on the top and bottom of the utility tunnel on the foot wall side and hanging wall side, respectively. With the increasing of intersection angle of utility tunnel and ground fissures, the axial stress was increased regardless of the same activity of ground fissures. It means that the tensile tress and compressive stress tend to decrease when intersection angle of utility tunnel and ground fissures decreases. Some scholars suggested that the metro and utility tunnel should orthogonally cross ground fissures in planning, but, according to the analysis, the maximum axial tensile stress occurred when utility tunnel orthogonally crossed ground fissures.

The result indicates that the axial tension stress was decreased with the decreasing of intersection angle. The maximum axial tension stress occurred when the utility tunnel orthogonally crossed ground fissures. 


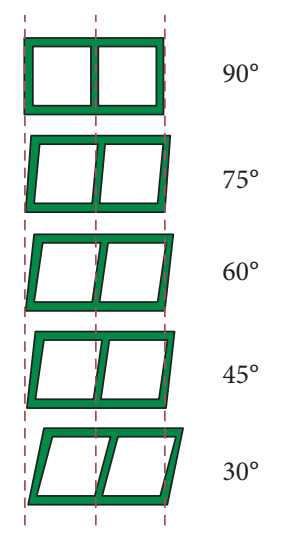

(a)

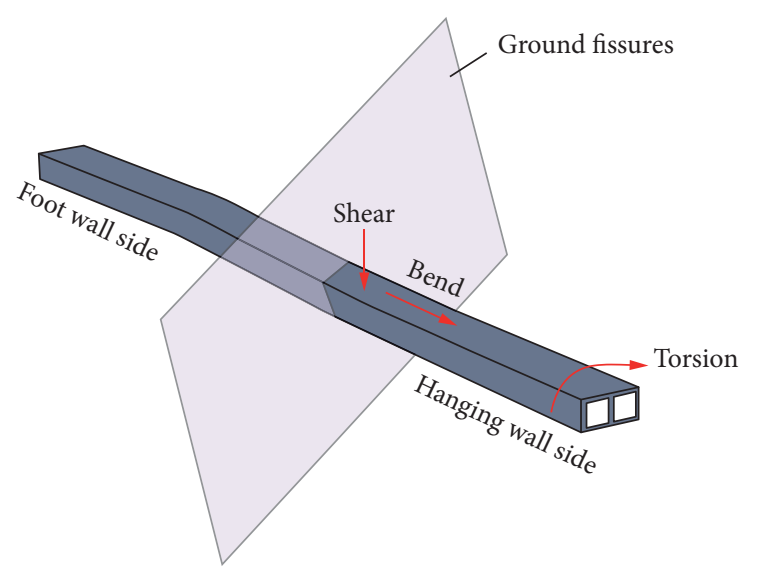

(b)

Figure 9: The deformation of the utility tunnel. (a) The trend of horizontal displacement in section with different intersection angle. (b) 3D illustration of the mechanism of deformation of utility tunnel.

3.3.2. Vertical Shear Stress. From the utility tunnel deformation analysis, the displacement in vertical direction was more significant than that in horizontal direction. Although the ultimate shear strength is bigger than ultimate tensile strength for concrete, it is necessary to analyze the failure mechanism of the utility tunnel in a state of complex stress. According to the observation of visualized color vertical shear stress cloud chart, it is easy to find that the shear stress was concentrated in the middle of the side walls and central wall. Therefore, the shear stress in vertical direction was analyzed through surveying line 5 to surveying line 8 in the middle of the side walls and central wall.

Figure 11 shows the shear stress in vertical direction with different conditions. The position of maximum shear stress was clearly revealed with the analysis of shear stress curves. No matter the variety of intersection angle between utility tunnel and ground fissures, the maximum shear stress appeared near the ground fissures. With the increasing of intersection angle between utility tunnel and ground fissures, the shear stress in vertical direction tended to decrease. Although the vertical displacement in each simulation mode was the same, the maximum shear stress in vertical direction was different with the variety of intersection angle. The shear stress characteristics in vertical direction well agree with the deformation characteristics. In addition, compared to the tension stress, the shear stress in vertical direction was much smaller.

3.3.3. Shear Stress in Horizontal Direction. Although the deformation and stress of utility tunnel are dominated by the activity of ground fissures, the intersection angle has some influence on the deformation and stress of utility tunnel more or less. From the aforementioned analysis of utility tunnel deformation, the deformation in horizontal direction was increased with the decreasing of the intersection angle. Therefore, the stress in horizontal direction should be considered.

The stress on the top of utility tunnel was analyzed due to the fact that the maximum displacement in horizontal direction of the utility tunnel occurred on the top. Therefore, surveying line 9 and surveying line 10 on the top of central wall were selected for analysis based on the observation of visualized color horizontal shear stress cloud chart. The shear stress in horizontal direction of two surveying lines is shown in Figure 12. Compared to the shear stress in vertical direction, the shear stress in horizontal direction was decreased significantly. The peak shear stresses occurred on the hanging wall and foot wall except the situation when the utility tunnel and ground fissures met at right angle. The shear stress in horizontal direction was increased when the intersection angle of utility tunnel and ground fissures decreased. Therefore, the horizontal displacement and shear stress in horizontal direction are related to the decrease of intersection angle.

Although there was a shear stress in horizontal direction on the top wall of the utility tunnel, it is still very small when comparing it to the tensile stress and shear stress in vertical direction. It does not mean that it is unnecessary to consider the shear stress in horizontal direction when utility tunnel crosses ground fissures with small intersection angle. Because the maximum horizontal displacement was almost $8 \mathrm{~cm}$, some utility lines will be dangerous when horizontal displacement is too big. Therefore, measures should be taken to decrease horizontal displacement when designing and building utility tunnel.

3.4. Equivalent Plastic Strain. Equivalent plastic strain is the cumulative result of plastic strain in the whole deformation process. In this paper, the equivalent plastic strain was analyzed on the top and bottom of the utility tunnel based on the deformation of the utility tunnel. Figure 13 shows the equivalent plastic strain along the axial direction.

From the above figure, it can be seen that when the intersection angle of utility tunnel and ground fissures is $90^{\circ}$, the area of equivalent plastic strain zone is bigger than any other conditions. This is due to the fact that the tensile stress is decreased when utility tunnel crosses ground fissures with a small angle. It is well known that ultimate tensile strength 


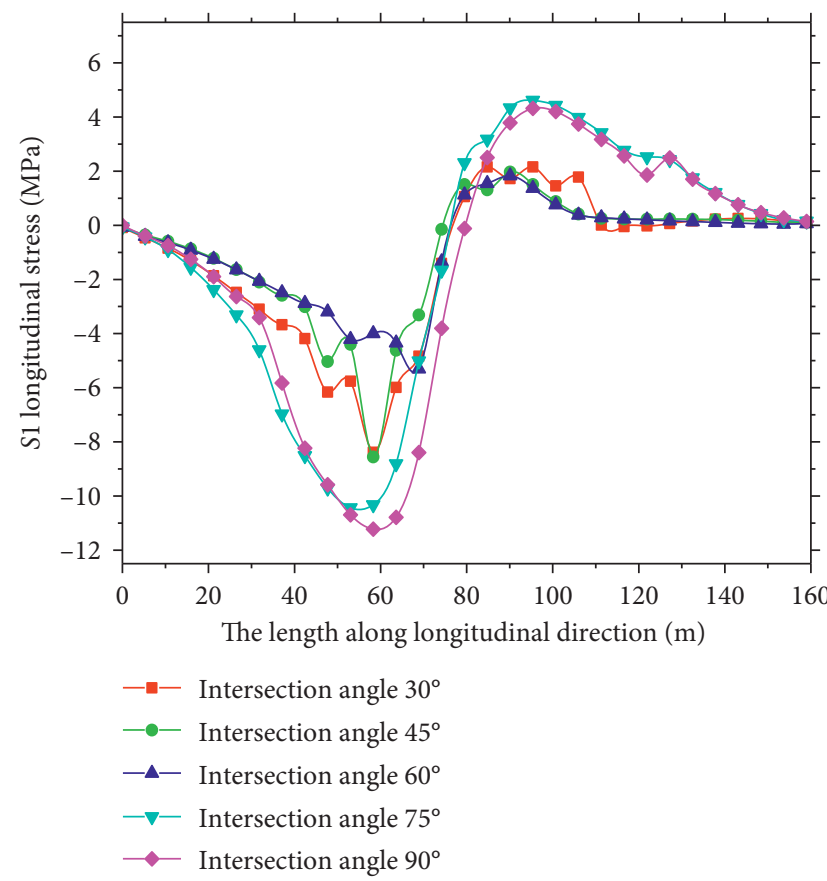

(a)

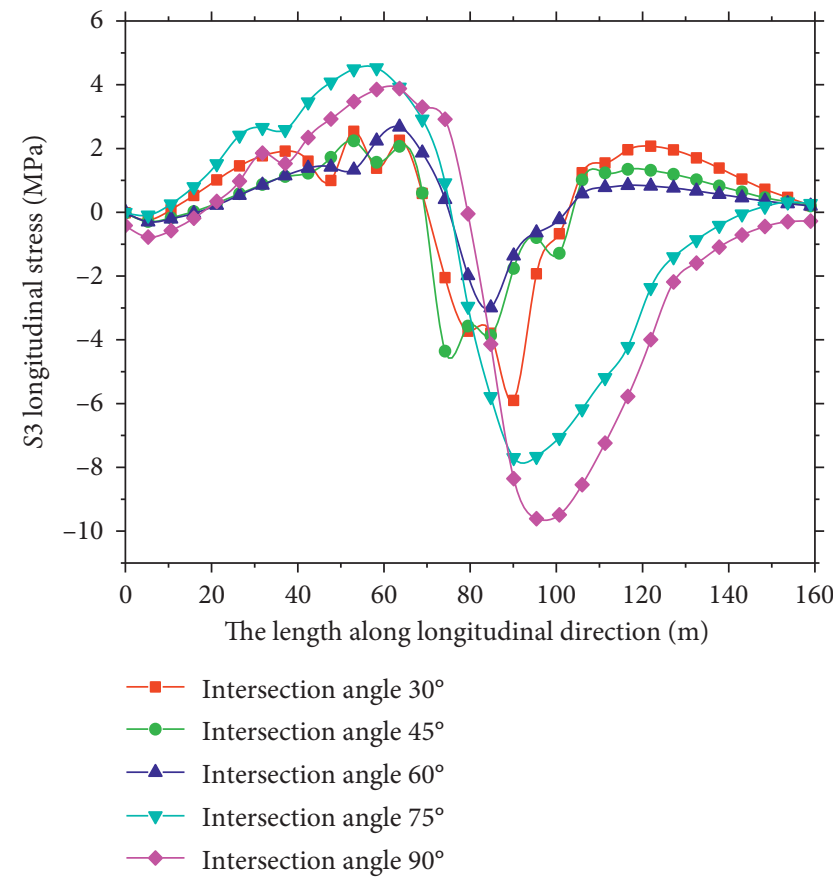

(c)

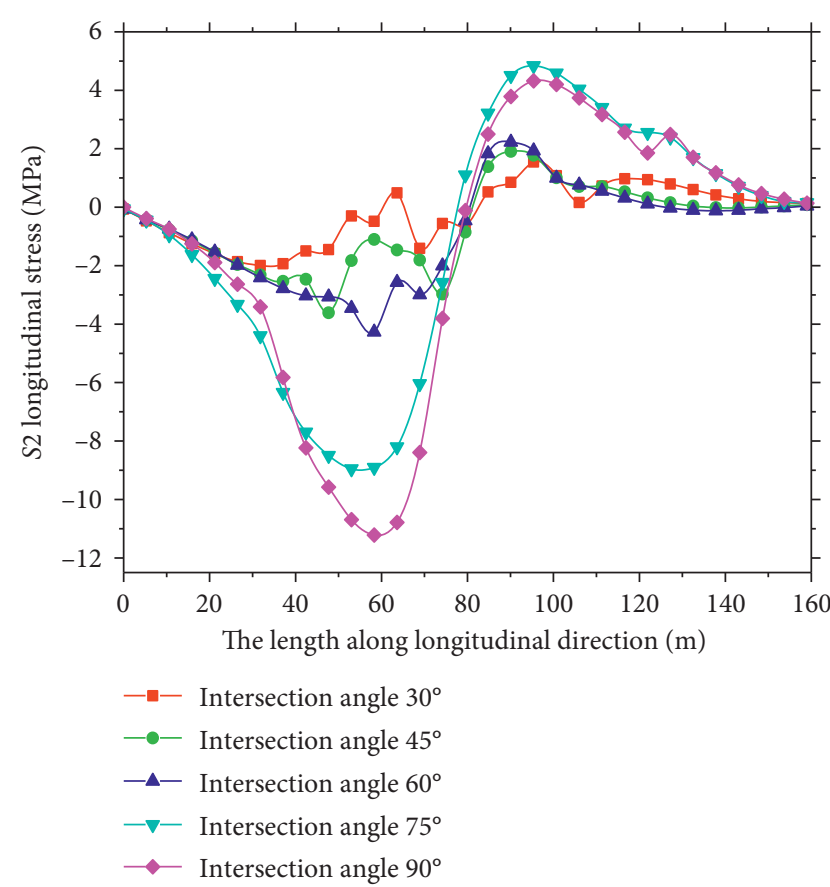

(b)

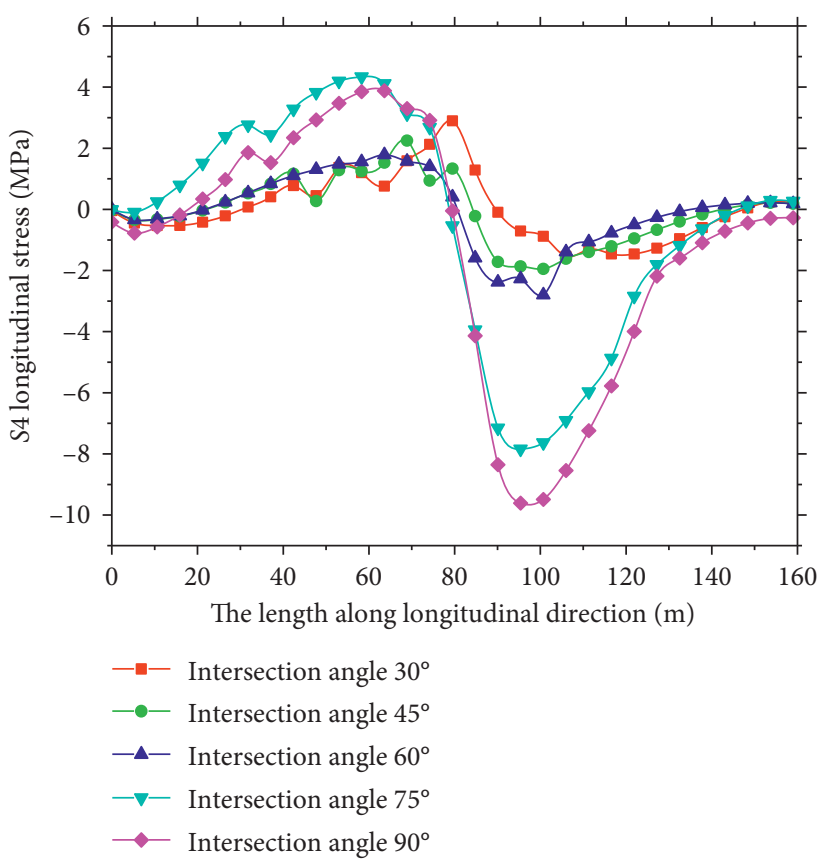

(d)

FIGURE 10: Axial tension stress with different intersection angle. (a) The axial tension stress of surveying line 1. (b) The axial tension stress of surveying line 2. (c) The axial tension stress of surveying line 3. (d) The axial tension stress of surveying line 4 .

of concrete is much smaller than the ultimate shear strength, so the equivalent plastic strain zone is dependent on the distribution of tensile stress. The equivalent plastic strain zone can help engineers to predict the failure and impact area of the utility tunnel. According to the figure of equivalent plastic strain, it is suggested that the strengthening length of utility tunnel should not be less than 50 meters (10 times the height of utility tunnel) on both sides of the ground fissures.

\section{Comparison and Analysis}

Prior study has found the effectiveness of ground fissures activity in conducting underground constructions and 


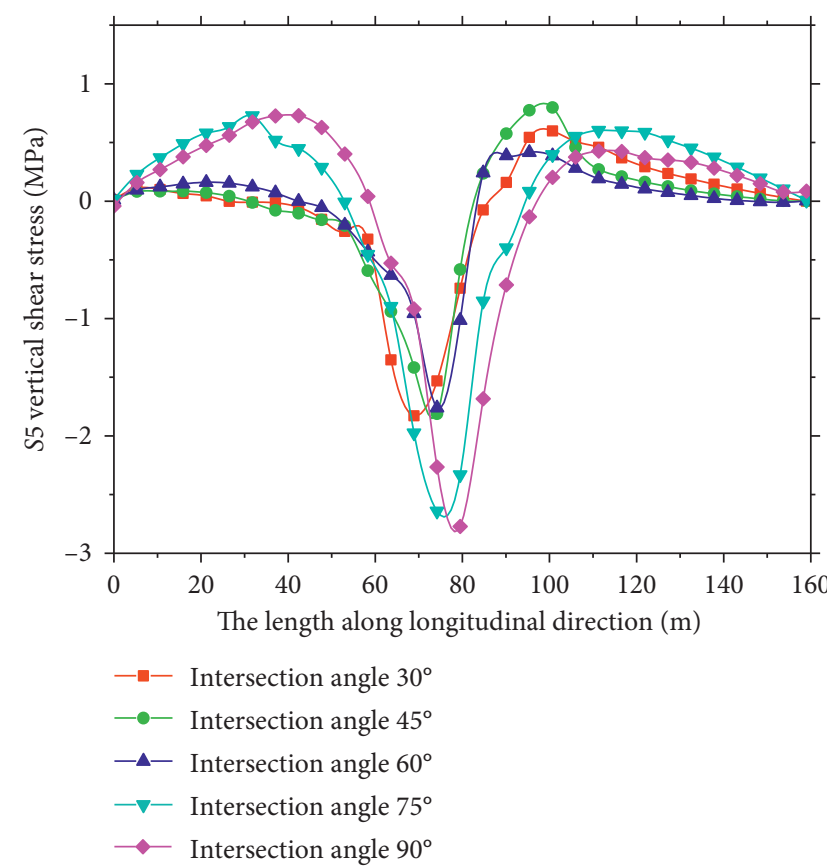

(a)

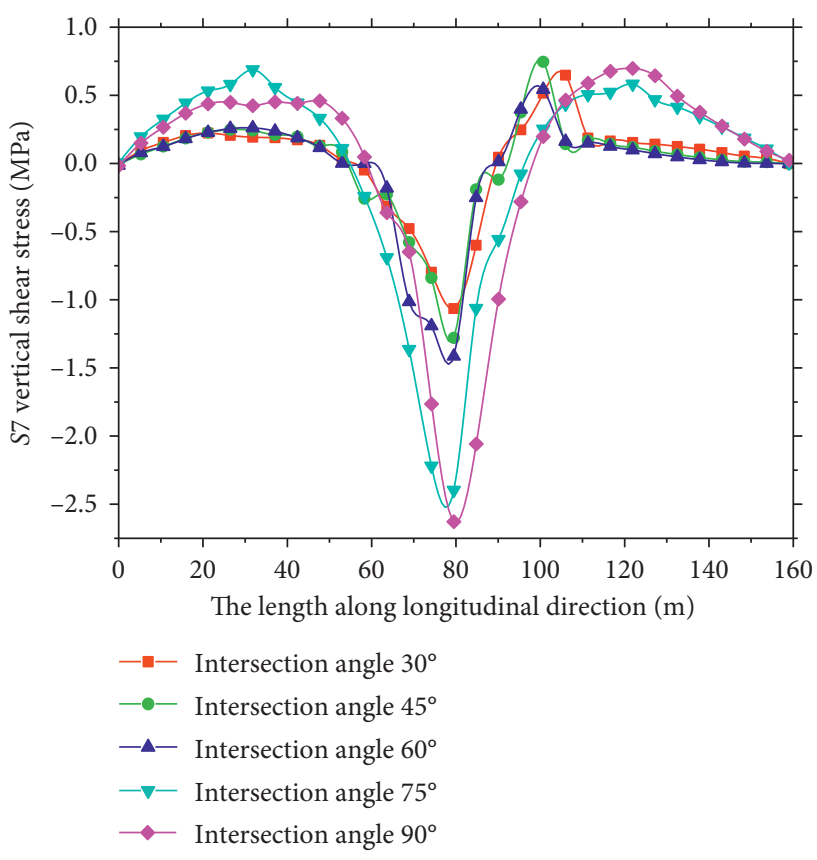

(c)

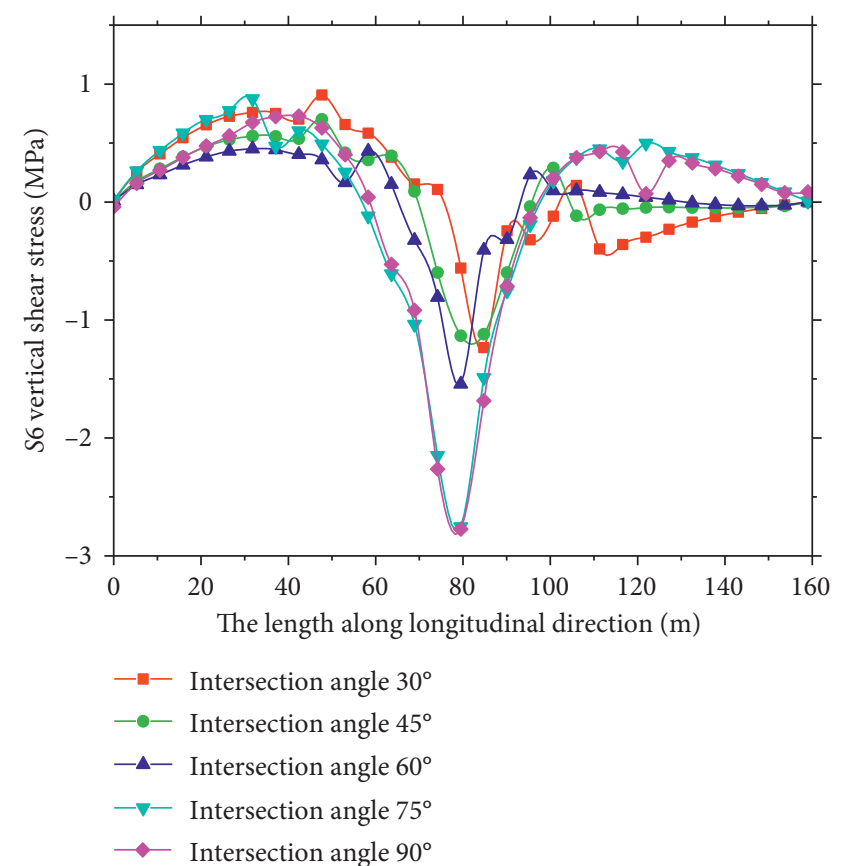

(b)

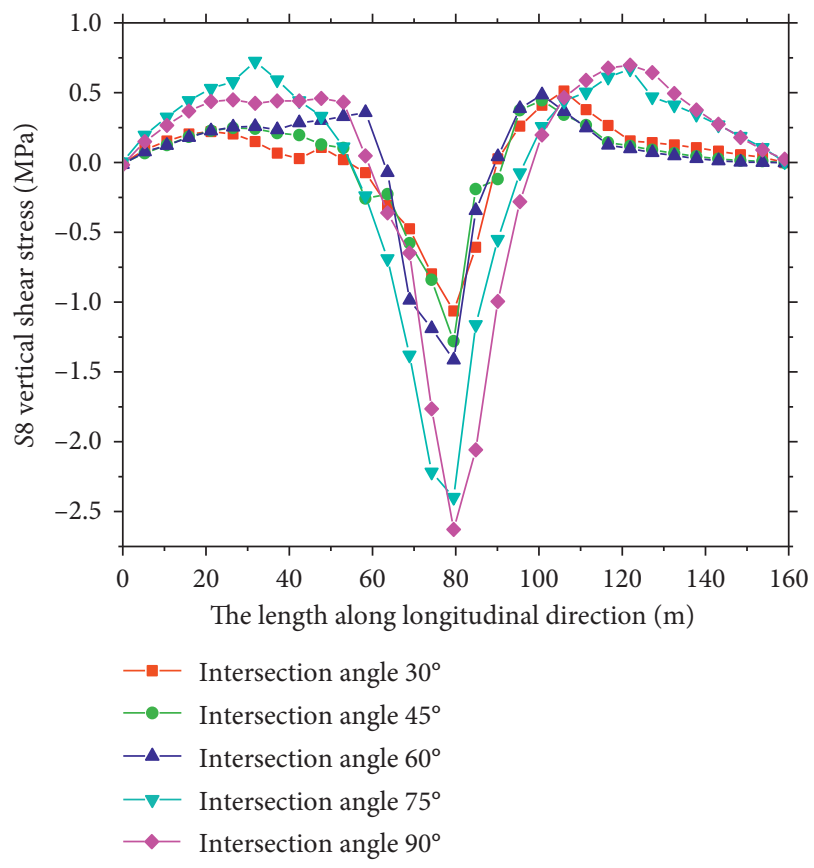

(d)

Figure 11: Vertical stress with different intersection angle. (a) The vertical stress of surveying line 5. (b) The vertical stress of surveying line 6. (c) The vertical stress of surveying line 7. (d) The vertical stress of surveying line 8.

control measures in underground structures affected by this kind of geological disasters. However, these studies have not compared the failure mechanism of utility tunnel when crossing ground fissures with different intersection angle. This paper compared the failure mechanism of utility tunnel through simulation method and proposed some suggestions.

It is found that, in virtually all cases, the tension stress in axial direction and shear stress in vertical direction were increased with intersection angle, but shear stress and displacement in horizontal direction were decreased when intersection angle increased. In addition, the equivalent plastic strain zone was also decreased with intersection angle. This study extended the previous research of metro tunnel and utility tunnel crossing ground fissures, with findings confirming that the tension stress and shear stress occur when they are not orthogonally crossing ground 


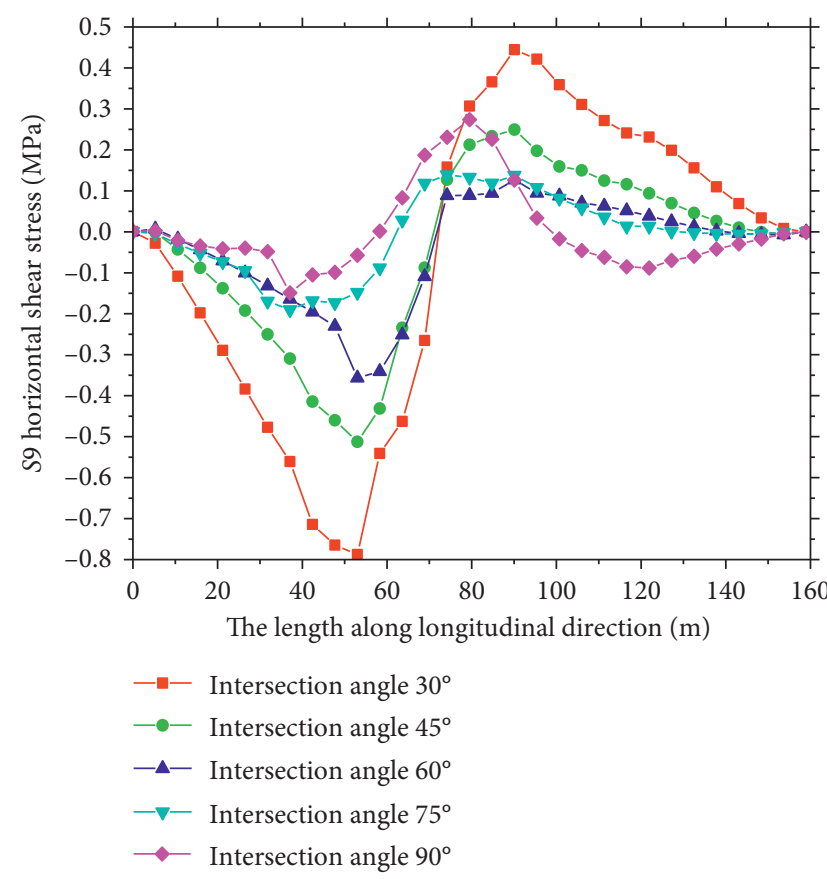

(a)

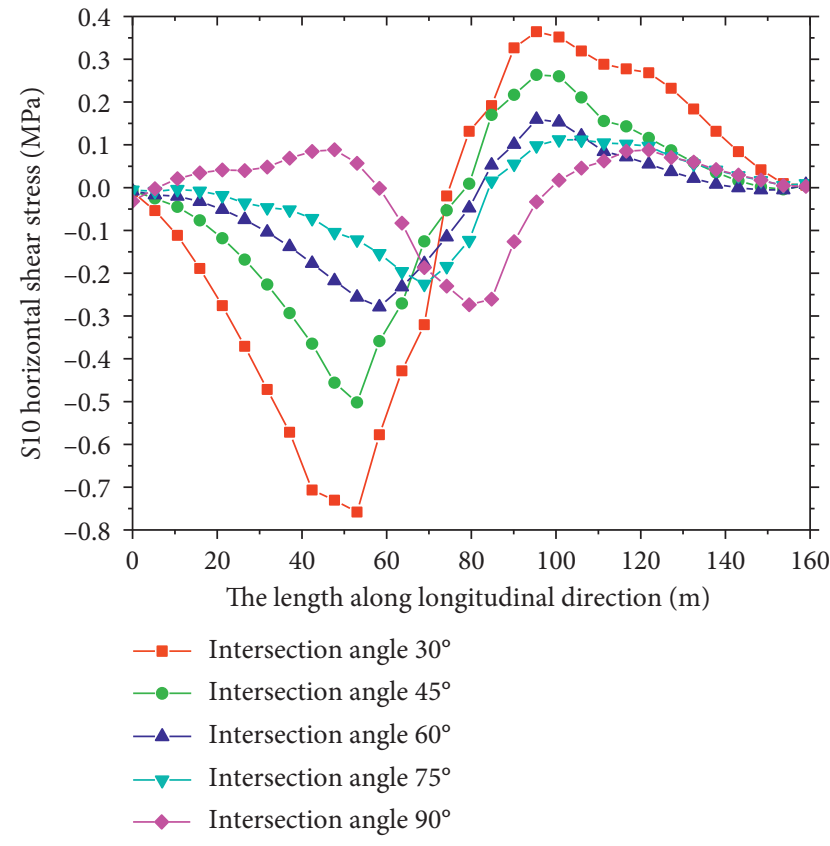

(b)

Figure 12: Shear stress in horizontal direction with different intersection angle. (a) The shear stress in horizontal direction of surveying line 9. (b) The shear stress in horizontal direction of surveying line 10.

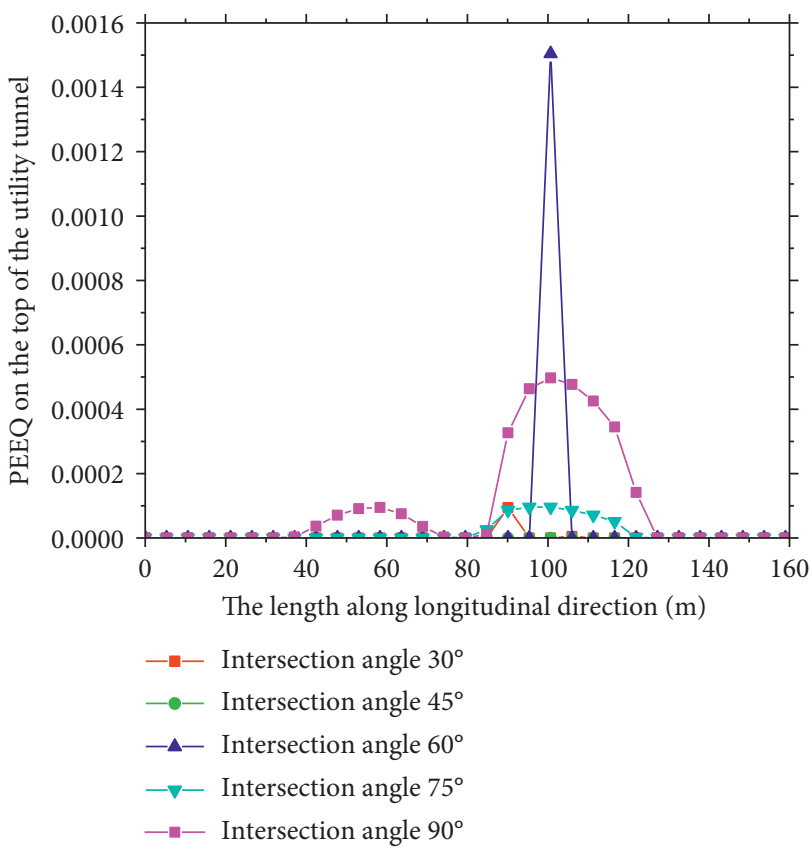

(a)

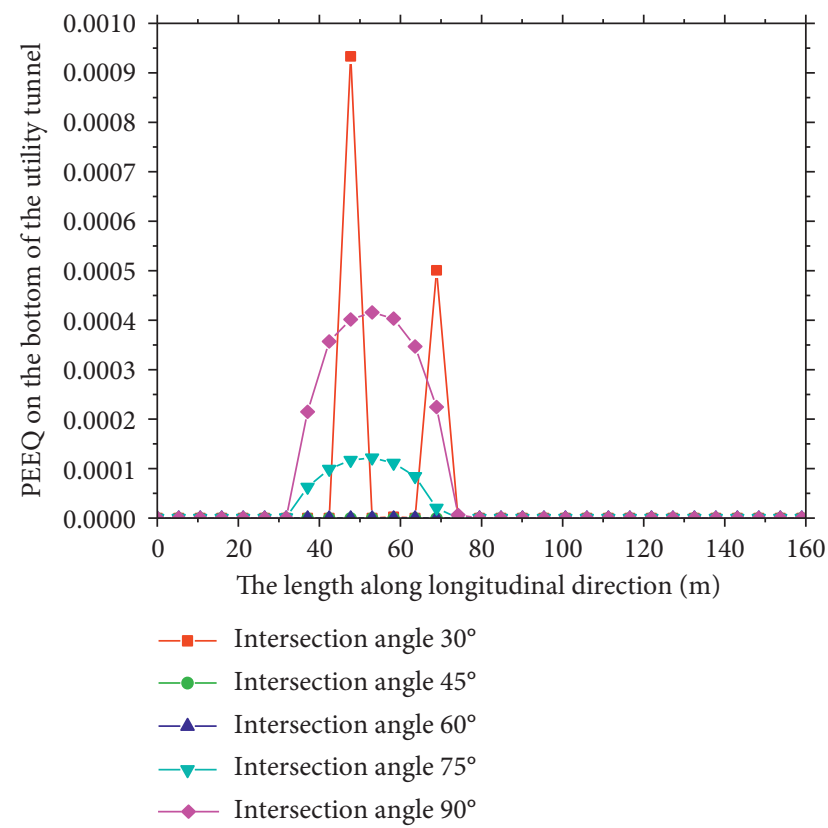

(b)

FIGURE 13: Equivalent plastic strain of the utility tunnel. (a) Equivalent plastic strain on the top of the utility tunnel. (b) Equivalent plastic strain on the bottom of the utility tunnel.

fissures (Figure 14). Table 3 shows the findings of the comparison between previous work and this paper. From the analysis of the data in the table, general characteristics of failure mechanism of the models in this paper agree well with prior findings, so the prevention and control measures of utility tunnel and metro tunnel maybe are the same. Furthermore, the characteristics of failure mechanism of utility tunnel with more intersection angles were compared in all cases. This study therefore indicates that the utility tunnel orthogonally crossing ground fissures cannot 


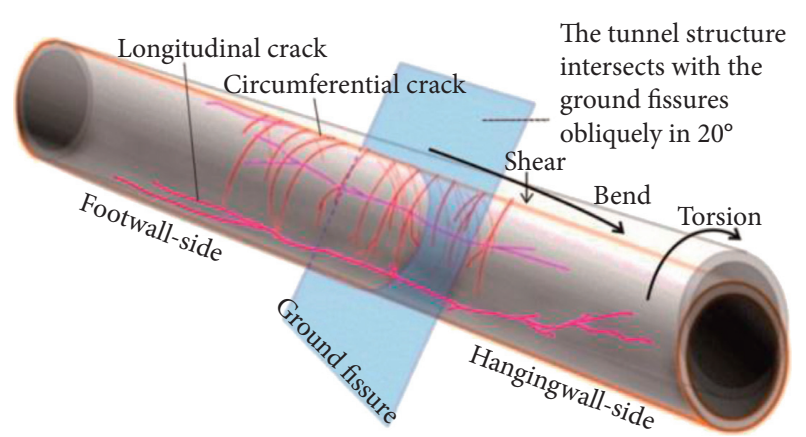

(a)

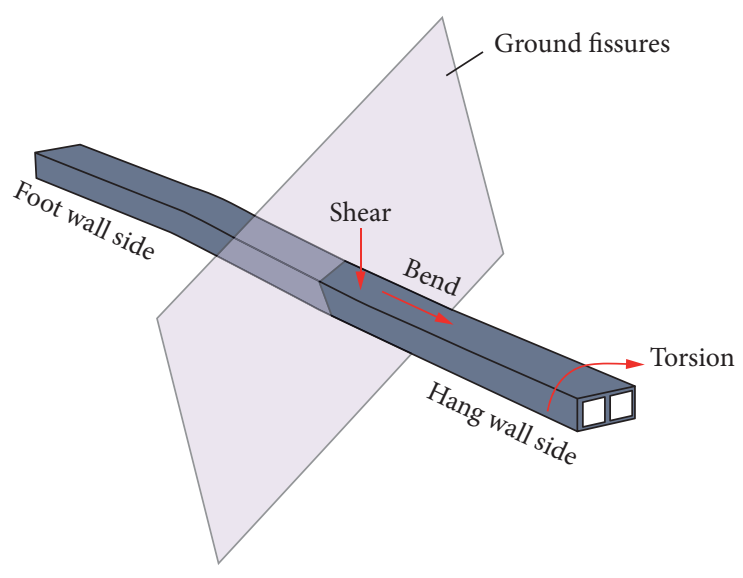

(b)

Figure 14: The comparison of general mechanical characteristics between previous research model and simulation model. (a) Previous research model [24]. (b) Simulation model in this paper.

TABLE 3: The findings of the comparison between prior research and this paper.

\begin{tabular}{|c|c|c|}
\hline Research model & $\begin{array}{l}\text { Conditions of intersection with } \\
\text { ground fissures }\end{array}$ & The characteristics of failure mechanism \\
\hline $\begin{array}{l}\text { Horseshoe-shaped } \\
\text { tunnel model }\end{array}$ & Orthogonal intersection & $\begin{array}{l}\text { Bending and tensile failure. Near the ground fissure, the upper and lower } \\
\text { surfaces of the tunnel were under tension and compression, respectively. The } \\
\text { deformation of the tunnel was symmetrical. [15]. }\end{array}$ \\
\hline $\begin{array}{l}\text { Horseshoe-shaped } \\
\text { tunnel mode }\end{array}$ & Oblique intersection & $\begin{array}{l}\text { Bending-torsional shearing failure under oblique intersection conditions. The } \\
\text { deformation of the tunnel was asymmetrical [15]. }\end{array}$ \\
\hline $\begin{array}{l}\text { Open-cut box tunnel } \\
\text { model }\end{array}$ & Orthogonal intersection & Bending and tensile failure. The deformation of the tunnel was symmetrical [15]. \\
\hline $\begin{array}{l}\text { Open-cut box tunnel } \\
\text { model }\end{array}$ & Oblique intersection & $\begin{array}{l}\text { Tensile-torsional shear failure mode, which is caused by the coupling of } \\
\text { longitudinal bending, torsion shearing deformation, and transverse bending } \\
\text { deformation. The deformation of the tunnel was asymmetrical [15]. }\end{array}$ \\
\hline$U$-shaped tunnel mode & Oblique intersection & $\begin{array}{l}\text { Tensile-torsional shear failure mode. The range in failure of the tunnel was up to } \\
3.5 \text { times the tunnel diameter on the hanging wall side and up to } 4.5 \text { times the } \\
\text { tunnel diameter on the foot wall. The deformation of the tunnel was } \\
\text { asymmetrical [24]. }\end{array}$ \\
\hline $\begin{array}{l}\text { The model in this } \\
\text { paper }\end{array}$ & Orthogonal intersection & $\begin{array}{l}\text { Bending and tensile failure. Near the ground fissure, the upper and lower } \\
\text { surfaces of the utility tunnel were under tension and compression, respectively. } \\
\text { The deformation of the tunnel was symmetrical. The range in failure of the utility } \\
\text { tunnel was up to } 10 \text { times the utility tunnel height on the hanging wall side and } \\
\text { up to } 10 \text { times the utility tunnel height on the foot wall. }\end{array}$ \\
\hline $\begin{array}{l}\text { The model in this } \\
\text { paper }\end{array}$ & Oblique intersection & $\begin{array}{l}\text { Tensile-torsional shear failure mode. The tension stress in horizontal direction } \\
\text { and shear stress vertical direction were increased with intersection angle, but } \\
\text { shear stress and displacement in horizontal direction were decreased with } \\
\text { intersection angle. The deformation of the tunnel was asymmetrical. }\end{array}$ \\
\hline
\end{tabular}

significantly reduce the damage of it. When planning the network of utility tunnel in ground fissures area, failure mechanism of utility tunnel, intersection angle, and utility lines should have comprehensive consideration before planning.

Most notably, to our knowledge, this is the first study to compare the characteristics of failure mechanism when utility tunnel crossing ground fissures with different intersection angle. The comparison results suggested that the variation of intersection angle cannot significantly reduce the damage of ground fissures activity. However, some defects of simulation model are worth noting. Although the simulation method cannot consider the slippage of reinforcing bar inside the concrete, the characteristics of deformation and stress agreed well with actual situations. Further work should compare the failure mechanism of utility tunnel via more experiments if research funds are not limited.

\section{Conclusions}

The following conclusions can be drawn from the present study regarding the utility tunnel crossing ground fissures with different intersection angle: 
(1) It cannot significantly decrease the damage of utility tunnel when changing the intersection angle of the utility tunnel and ground fissures. The tension stress in axial direction and shear stress of the utility tunnel in vertical direction were increased with the intersection angle, but shear stress and displacement of utility tunnel in horizontal direction were increased when intersection angle decreased.

(2) The deformation outline of the utility tunnel looks like an " $S$ " curve when crossing ground fissures. Vertical displacement of utility tunnel does not have big relationship with the intersection angle. The horizontal displacement of utility tunnel increases with the decreases of intersection angle. This paper suggests that measures should be taken to reduce horizontal displacement of utility tunnel when building and designing it with a small intersection angle.

(3) No matter the variation of intersection angle of utility tunnel and ground fissures, when designing utility tunnel in ground fissures area, it is suggested that the strengthening length of utility tunnel should not be less than 50 meters (10 times the height of utility tunnel) on both sides of the ground fissures.

\section{Data Availability}

All data, models, and code generated or used during the study appear in the submitted article. Some or all data, models, or code that support the findings of this study are available from the corresponding author upon reasonable request (simulation models).

\section{Conflicts of Interest}

The authors declare that they have no conflicts of interest.

\section{Acknowledgments}

The authors acknowledge the support by Natural Science Foundation of Shaanxi Province (Grant no. 2017ZDXM-SF095).

\section{References}

[1] T. Wang, L. Tan, S. Xie, and B. Ma, "Development and applications of common utility tunnels in China," Tunnelling and Underground Space Technology, vol. 76, pp. 92-106, 2018.

[2] F. Qu, Q. Zhang, Z. Lu, C. Zhao, C. Yang, and J. Zhang, "Land subsidence and ground fissures in Xi'an, China 2005-2012 revealed by multi-band InSAR time-series analysis," Remote Sensing of Environment, vol. 155, pp. 366-376, 2014.

[3] J. Peng, J. Qiao, Y. Leng, F. Wang, and S. Xue, "Distribution and mechanism of the ground fissures in wei river basin, the origin of the silk road," Environmental Earth Sciences, vol. 75, no. 8, 2016.

[4] X. Y. Wang, S. H. Mao, and Y. J. Zhang, "Differential settlement due to ground fissures in xi'an," Advanced Materials Research, vol. 1065-1069, pp. 410-413, 2014.
[5] A. M. Youssef, A. A. Sabtan, N. H. Maerz, and Y. A. Zabramawi, "Earth fissures in wadi najran, kingdom of Saudi Arabia," Natural Hazards, vol. 71, no. 3, pp. 2013-2027, 2014.

[6] J. Canto-Perello and J. Curiel-Esparza, "Assessing governance issues of urban utility tunnels," Tunnelling and Underground Space Technology, vol. 33, pp. 82-87, 2013.

[7] J. Canto-Perello and J. Curiel-Esparza, "An analysis of utility tunnel viability in urban areas," Civil Engineering and Environmental Systems, vol. 23, no. 1, pp. 11-19, 2006.

[8] J. Curiel-Esparza, M. A. J. Canto-Perello, and M. A. Calvo, "Establishing sustainable strategies in urban underground engineering," Science and Engineering Ethics, vol. 10, no. 3, pp. 523-530, 2004.

[9] J. Canto-Perello, J. Curiel-Esparza, and V. Calvo, "Analysing utility tunnels and highway networks coordination dilemma," Tunnelling and Underground Space Technology Incorporating Trenchless Technology Research, vol. 24, no. 2, pp. 185-189, 2008.

[10] J. Canto-Perello, J. Curiel-Esparza, and V. Calvo, "Criticality and threat analysis on utility tunnels for planning security policies of utilities in urban underground space," Expert Systems With Applications, vol. 40, no. 11, pp. 4707-4714, 2013.

[11] J. Canto-Perello, J. Curiel-Esparza, and V. Calvo, "Strategic decision support system for utility tunnel's planning applying A'WOT method," Tunnelling and Underground Space Technology Incorporating Trenchless Technology Research, vol. 55, pp. 146-152, 2016.

[12] C. Yang, F.-L. Peng, K. Xu, and Li-N. Zheng, "Feasibility study on the geothermal utility tunnel system," Sustainable Cities and Society, vol. 46, Article ID 101445, 2019.

[13] J. Chen, J. L. Jiang, and X. Shi, "Numerical simulation of shaking table test on utility tunnel under non-uniform earthquake excitation," Tunnelling and Underground Space Technology, vol. 30, no. none, pp. 205-216, 2012.

[14] J. Li, Q. Yue, and J. Chen, "Dynamic response of utility tunnel during the passage of Rayleigh waves," Earthquake Science, vol. 23, no. 1, pp. 13-24, 2010.

[15] J.-B. Peng, Q.-B. Huang, Z.-P. Hu et al., "A proposed solution to the ground fissure encountered in urban metro construction in Xi' an, China," Tunnelling and Underground Space Technology, vol. 61, pp. 12-25, 2017.

[16] Z. F. Wang, S. L. Shen, W. C. Cheng et al., "Ground fissures in Xi'an and measures to prevent damage to the Metro tunnel system due to geohazards," Environmental Earth Sciences, vol. 75, no. 6, p. 511, 2016.

[17] N. Liu, Q. Huang, and J. Peng, et al., "Experimental study of a segmented metro tunnel in a ground fissure area," Soil $D y$ namics and Earthquake Engineering, vol. 100, pp. 410-416, 2017.

[18] Z.-Y. Yen, P. Wang, and F. Zhang, "Effect of particle shape on the progressive failure of shield tunnel face in granular soils by coupled FDM-DEM method," Tunnelling and Underground Space Technology, vol. 100, Article ID 103394, 2020.

[19] P. Wang and Z.-Y. Yin, "Micro-mechanical analysis of caisson foundation in sand using DEM," Ocean Engineering, vol. 203, Article ID 107240, 2020.

[20] P. Wang, N. Gao, K. Ji, L. Stewart, and C. Arson, "DEM analysis on the role of aggregates on concrete strength," Computers and Geotechnics, vol. 119, Article ID 103290, 2019.

[21] P. Wang, Z. Karatza, and C. Arson, "DEM modelling of sequential fragmentation of zeolite granules under oedometric 
compression based on XCT observations," Powder Technology, vol. 347, pp. 66-75, 2019.

[22] GB 50010 4, Ministry of Housing and Urban-Rural Construction of the People's Republic of China. Code for Design of Concrete Structures, Chinese Building Industry Press, Beijing, China, 2011.

[23] J.-B. Peng, L.-W. Chen, Q.-B. Huang, Y.-M. Men, W. Fan, and J.-K. Yan, "Physical simulation of ground fissures triggered by underground fault activity," Engineering Geology, vol. 155, pp. 19-30, 2013.

[24] J. Peng, K. He, X. Tong, Q. Huang, and C. Liu, "Failure mechanism of an underground metro tunnel intersecting steep ground fissure at low angle," International Journal of Geomechanics, vol. 17, no. 5, 2016. 